\title{
Preoperative anemia versus blood transfusion: Which is the culprit for worse outcomes in cardiac surgery?
}

Damien J. LaPar, MD, MSc, ${ }^{\text {a }}$ Robert B. Hawkins, MD, MSc, ${ }^{a}$ Timothy L. McMurry, PhD,

James M. Isbell, MD, MSCI, ${ }^{a}$ Jeffrey B. Rich, MD, ${ }^{b}$ Alan M. Speir, MD, ${ }^{c}$ Mohammed A. Quader, MD, ${ }^{d}$ Irving L. Kron, MD, ${ }^{a}$ John A. Kern, MD, ${ }^{a}$ and Gorav Ailawadi, MD, ${ }^{a}$ Investigators for the Virginia Cardiac Services Quality Initiative

\section{ABSTRACT}

Background: Reducing blood product utilization after cardiac surgery has become a focus of perioperative care as studies have suggested improved outcomes. The relative impact of preoperative anemia versus packed red blood cells (PRBC) transfusion on outcomes remains poorly understood, however. In this study, we investigated the relative association between preoperative hematocrit (Hct) level and PRBC transfusion on postoperative outcomes after coronary artery bypass grafting $(\mathrm{CABG})$ surgery.

Methods: Patient records for primary, isolated CABG operations performed between January 2007 and December 2017 at 19 cardiac surgery centers were evaluated. Hierarchical logistic regression modeling was used to estimate the relationship between baseline preoperative Hct level as well as PRBC transfusion and the likelihoods of postoperative mortality and morbidity, adjusted for baseline patient risk. Variable and model performance characteristics were compared to determine the relative strength of association between Hct level and PRBC transfusion and primary outcomes.

Results: A total of 33,411 patients (median patient age, 65 years; interquartile range [IQR], 57-72 years; $26 \%$ females) were evaluated. The median preoperative Hct value was 39\% (IQR, 36\%-42\%), and the mean Society of Thoracic Surgeons (STS) predicted risk of mortality was $1.8 \pm 3.1 \%$. Complications included PRBC transfusion in $31 \%$ of patients, renal failure in $2.8 \%$, stroke in $1.3 \%$, and operative mortality in $2.0 \%$. A strong association was observed between preoperative Hct value and the likelihood of PRBC transfusion $(P<.001)$. After risk adjustment, PRBC transfusion, but not Hct value, demonstrated stronger associations with postoperative mortality (odds ratio $[\mathrm{OR}], 4.3 ; P<.0001$ ), renal failure (OR 6.3; $P<.0001$ ), and stroke (OR, 2.4; $P<.0001)$. A 1-point increase in preoperative Hct was associated with decreased probabilities of mortality (OR, 0.97; $P=.0001)$ and renal failure (OR, $0.94 ; P<.0001)$. The models with PRBC had superior predictive power, with a larger area under the curve, compared with Hct for all outcomes (all $P<.01$ ). Preoperative anemia was associated with up to a 4-fold increase in the probability of PRBC transfusion, a 3-fold increase in renal failure, and almost double the mortality.

Conclusions: PRBC transfusion appears to be more closely associated with riskadjusted morbidity and mortality compared with preoperative Hct level alone, supporting efforts to reduce unnecessary PRBC transfusions. Preoperative anemia independently increases the risk of postoperative morbidity and mortality. These

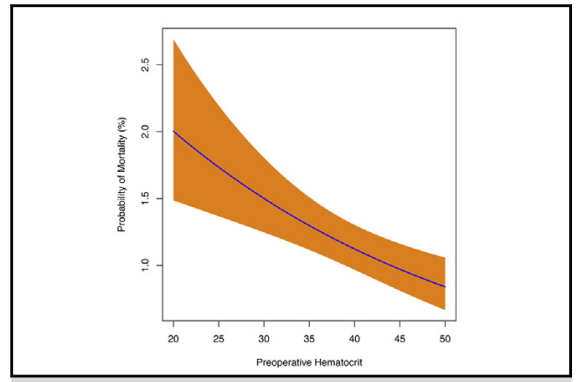

Risk-adjusted impact of preoperative hematocrit versus mortality following primary, isolated coronary artery bypass grafting surgery.

\section{Central Message}

PRBC transfusion was a stronger risk factor for morbidity and mortality than preoperative hematocrit level, supporting efforts to reduce unnecessary PRBC transfusions.

\section{Perspective}

Both preoperative anemia and PRBC transfusion are linked with poor outcomes after CABG. This study identified PRBC transfusion as a stronger risk factor for worse mortality and morbidity. This finding supports efforts to reduce unnecessary $\mathrm{PRBC}$ transfusions and to optimize hematocrit before surgery. Finally, hematocrit should be considered for inclusion in the STS risk models.

See Editorial Commentary page 75 .

See Editorial page 64.
From the ${ }^{\mathrm{a}}$ University of Virginia, Charlottesville, Va; ${ }^{\mathrm{b}}$ Sentara Heart Hospital, Norfolk, Va; Inova Heart and Vascular Institute, Falls Church, Va; and ${ }^{\mathrm{d}}$ Virginia Commonwealth University, Richmond, Va.

Read at the 95th Annual Meeting of The American Association for Thoracic Surgery, Seattle, Washington, April 25-29, 2015.

Received for publication May 14, 2015; revisions received Feb 5, 2018; accepted for publication March 2, 2018; available ahead of print April 26, 2018.
Address for reprints: Gorav Ailawadi, MD, Department of Surgery, University of Virginia, PO Box 800679, Charlottesville, VA 22908 (E-mail: gorav@ virginia.edu). $0022-5223 / \$ 36.00$

Copyright $(C) 2018$ by The American Association for Thoracic Surgery https://doi.org/10.1016/j.jtcvs.2018.03.109 

Abbreviations and Acronyms
AUC = area under the curve
$\mathrm{CABG}=$ coronary artery bypass grafting
Hct $=$ hematocrit
IQR = interquartile range
PRBC $=$ packed red blood cells
STS = Society of Thoracic Surgeons
TRALI $=$ transfusion-related acute lung injury
VCSQI = Virginia Cardiac Services Quality Initiative

\section{Scanning this $\mathrm{QR}$ code will take you to the supplemental tables. To view the AATS Annual Meeting Webcast, see the URL next to the webcast thumbnail.

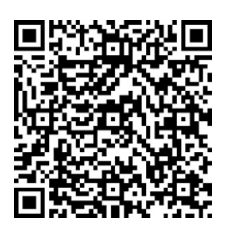

data suggest that preoperative Hct should be included in the STS risk calculators. Finally, efforts to optimize preoperative hematocrit should be investigated as a potentially modifiable risk factor for mortality and morbidity. (J Thorac Cardiovasc Surg 2018;156:66-74)

Coronary artery bypass grafting $(\mathrm{CABG})$ remains one of the most commonly performed surgical operations in the United States and worldwide. Cardiac surgical procedures are estimated to be responsible for nearly $20 \%$ of the annual blood transfusions in the United States, ${ }^{1}$ and blood transfusion following CABG has been reported to occur in up to $60 \%$ of cases. ${ }^{2,3}$ Transfusion of allogenic blood products has been associated with significant adverse patient effects, including the occurrence of transfusion reactions, transfusion-related acute lung injury, immunosuppression and immunomodulation, infectious complications, and even reduced long-term survival. ${ }^{2,4-15}$ Although several series have investigated the independent effects of perioperative anemia and transfusion with packed red blood cells (PRBC), a fundamental question remains unanswered. Which factor (anemia or transfusion) contributes more to adverse cardiac surgical morbidity and mortality? Previous investigations have been frequently limited by examination of single-institution cohort analyses and heterogeneous surgical patient populations, and have failed to consider the nonlinear relationship between preoperative hematocrit (Hct) level and riskadjusted mortality and morbidity.
The purpose of the present study was to investigate the relative association between preoperative Hct versus PRBC transfusion on postoperative outcomes after CABG alone. We hypothesized that (1) a significant nonlinear relationship exists between preoperative Hct level and patient outcomes, as well as the need for PRBC transfusion, and (2) PRBC transfusion would have a stronger relative strength of association with postoperative mortality and morbidity compared with preoperative Hct level alone.

\section{METHODS}

The Virginia Cardiac Services Quality Initiative (VCSQI) consists of 19 cardiac surgical centers within Virginia and North Carolina. VCSQI centers perform approximately $99 \%$ of Virginia's cardiac operations, contributing patient data to the Society of Thoracic Surgeons (STS) Adult Cardiac Surgery Database. This study was exempt from formal Institutional Review Board review at each participating hospital, owing to the secondary analysis of the VCSQI's deidentified (ie, absence of Health Insurance Portability and Accountability Act patient identifiers) data registry and because the data were collected for quality analysis and purposes other than research.

\section{Patients and Data Acquisition}

Deidentified patient data were extracted from the VCSQI data registry for the study period January 1, 2007, to December 31, 2017. The records included patients undergoing primary (ie, no previous sternotomy) isolated CABG operations (STS procedure type "CAB Alone"). Patients who had missing preoperative Hct data or had undergone a concomitant valve procedure or other cardiac surgery were excluded. All CABG surgeries involved standard open surgical approaches to myocardial surgical revascularization with and without the use of cardiopulmonary bypass support. Patients' preoperative risk was assessed based on the presence of comorbidities, operative status, and individual calculated STS predicted risk score.

The primary outcomes of interest included risk-adjusted association between preoperative Hct level versus PRBC transfusion and the probability of operative mortality and measures of major morbidity, including likelihood of PRBC transfusion, renal failure, or stroke. PRBC transfusion was defined as either intraoperative or postoperative, both of which were correlated with postoperative complications. Standard STS clinical definitions were used for all analyzed variables. ${ }^{16}$

\section{Statistical Analysis}

For descriptive statistics, categorical variables are expressed as group percentages, and continuous variables are expressed as either mean \pm standard deviation or median (interquartile range [IQR]), depending on overall variable distribution. Generalized linear mixed regression models were used to estimate the relationships between baseline preoperative Hct level and PRBC transfusion with the likelihood of postoperative mortality and morbidity, adjusted for baseline patient risk. Preoperative Hct values $<17 \%$ or $>54 \%$ were excluded, and the remaining values were modeled as a continuous function. Hct values were centered at their mean, $38.855 \%$, to facilitate the convergence of the statistical models. The predicted associations between preoperative Hct level or PRBC transfusion and outcomes were adjusted for the confounding effects of preoperative patient risk profile (STS predicted risk scores) and year through the inclusion of these variables as model covariates. STS predicted risk scores were logit-transformed, which put them on the natural scale for inclusion as predictors in a logistic model. Hospital was included in the model as a random effect to account for clustering at the hospital level. The relative strength of association between Hct level versus PRBC transfusion and 
the probability of mortality or morbidity was determined by comparing adjusted odds ratios (ORs), $P$ values, and area under the curve (AUC) values for each model. The AUC values from the corresponding Hct and PRBC models were compared using DeLong's test. In addition, the riskadjusted functions of Hct level versus the probability of mortality and measures of major morbidity were graphically represented to provide better explanatory power. Patients with missing data were excluded from the corresponding summary statistic. For regression analysis, missing values were imputed with the lowest risk categorical predictors (eg, no PRBC) or as nonevents for outcome variables. A 2 -sided $P$ value $<0.05$ defined statistically significant variable associations. All statistical analyses were performed using R version 3.4.3 (http://www.R-project.org).

\section{RESULTS \\ Patient Characteristics and Operative Features for CABG Surgery}

A total of 33,411 patients underwent primary, isolated CABG surgery. Table 1 presents descriptive statistics and frequencies of patient preoperative and operative characteristics. The median patient age was 65 years (IQR, 5772 years), and females comprised $26 \%$ of the cohort. The mean STS predicted risk of mortality was $1.8 \pm 3.1 \%$. The most prevalent comorbid disease states included hypertension, dyslipidemia, diabetes, and cerebrovascular disease. The majority of patients presented without symptoms of heart failure. The median ejection fraction was $55 \%$ (IQR, $45 \%-60 \%$ ). The majority of patients presented with 3-vessel coronary artery disease, and significant left main coronary artery disease was present in one-third of patients. The median preoperative Hct value was 39\% (IQR, 36\%-42\%) for the study population. Figure 1 displays the distribution of preoperative Hct levels for the study population.

The majority of the CABG operations were performed in either an elective $(35 \%)$ or urgent $(61 \%)$ setting, with few done on emergent basis. CABG was performed with cardiopulmonary bypass support in $91 \%$ of cases. Off-pump CABG was performed in $8 \%$ of operations, and a combination of bypass support was provided in $1 \%$ of patients. The median cardiopulmonary bypass time was 92 minutes (IQR, 72-115 minutes), and the median aortic cross-clamp time was 67 minutes (IQR, 51-85 minutes). Left internal mammary artery conduits were used in $95 \%$ of cases; bilateral internal mammary artery conduits, in 3\% of cases. The median lowest intraoperative Hct level was 25\% (IQR, 21\%$28 \%$ ).

\section{Postoperative Outcomes Following CABG Operations}

Table 2 displays the frequency of postoperative events and outcomes. Nearly one-third of patients received postoperative blood product transfusions; in those patients, the median number of PRBC units transfused was 2 (IQR, 14). Detailed intraoperative and postoperative transfusion rates are available in Table E1. The most common
TABLE 1. Descriptive statistics of preoperative and operative characteristics for patients undergoing primary, isolated CABG surgery $(\mathbf{n}=\mathbf{3 3 , 4 1 1})$

\begin{tabular}{|c|c|}
\hline Characteristic & Value \\
\hline \multicolumn{2}{|l|}{ Patient characteristics } \\
\hline Age, y, median (IQR) & $65(57-72)$ \\
\hline Female sex, n $(\%)$ & $8569(25.7)$ \\
\hline Body mass index, $\mathrm{kg} / \mathrm{m}^{2}$, median (IQR) & $29(26-33)$ \\
\hline Cerebrovascular disease, $\mathrm{n}(\%)$ & $5586(16.8)$ \\
\hline Stroke, n (\%) & $2054(6.4)$ \\
\hline \multicolumn{2}{|l|}{ Chronic lung disease, $\mathrm{n}(\%)$} \\
\hline Mild & $4554(13.9)$ \\
\hline Moderate & $1744(5.3)$ \\
\hline Severe & $1283(3.9)$ \\
\hline Hypertension & $28,911(86.6)$ \\
\hline Diabetes & $14,824(44.4)$ \\
\hline Peripheral arterial disease & $4526(13.6)$ \\
\hline Renal failure (hemodialysis) & $994(3.0)$ \\
\hline \multicolumn{2}{|l|}{ NYHA class, $n(\%)$} \\
\hline None & $27,201(82.7)$ \\
\hline I & $479(1.5)$ \\
\hline II & $1921(5.8)$ \\
\hline III & $2127(6.5)$ \\
\hline IV & $1176(3.6)$ \\
\hline Ejection fraction, $\%$, median (IQR) $(\mathrm{n}=21,199)$ & $55(45-60)$ \\
\hline Left main disease $>50 \%, \mathrm{n}(\%)$ & 7877 (33.2) \\
\hline \multicolumn{2}{|l|}{ Number of disease vessels, $\mathrm{n}(\%)$} \\
\hline 1 & $1368(4.1)$ \\
\hline 2 & $6438(19.3)$ \\
\hline 3 or more & $25,490(76.6)$ \\
\hline Last preoperative hematocrit, \%, median (IQR) & $39(36-42)$ \\
\hline Predicted risk of mortality, $\%$, median (IQR) & $1.8 \pm 3.1$ \\
\hline \multicolumn{2}{|l|}{ Operative characteristics } \\
\hline \multicolumn{2}{|l|}{ Cardiopulmonary bypass support, $\mathrm{n}(\%)$} \\
\hline None & $2722(8.2)$ \\
\hline Full & $30,472(91.2)$ \\
\hline Combination & $216(0.7)$ \\
\hline \multicolumn{2}{|l|}{ Operative status, n (\%) } \\
\hline Elective & $11,658(34.9)$ \\
\hline Urgent & $20,447(61.2)$ \\
\hline Emergent & $1254(3.8)$ \\
\hline Emergent salvage & $46(0.1)$ \\
\hline Cardiopulmonary bypass time, min, median (IQR) & $92(72-115)$ \\
\hline Aortic cross-clamp time, min, median (IQR) & $67(51-85)$ \\
\hline Lowest intraoperative Hct, \%, median (IQR) & $25(21-28)$ \\
\hline \multicolumn{2}{|l|}{ IMA use, $\mathrm{n}(\%)$} \\
\hline No IMA & $1646(4.9)$ \\
\hline Left IMA & $30,604(91.7)$ \\
\hline Right IMA & $175(0.5)$ \\
\hline Both IMA & $961(2.9)$ \\
\hline
\end{tabular}

$I Q R$, Interquartile range; NYHA, New York Heart Association; IMA, internal mammary artery.

postoperative complication was atrial fibrillation $(20 \%)$. Prolonged mechanical ventilation was provided in $9 \%$ of patients. Renal failure occurred in 3\% of patients; stroke, in $1.3 \%$. Operative mortality was $2.0 \%$. 


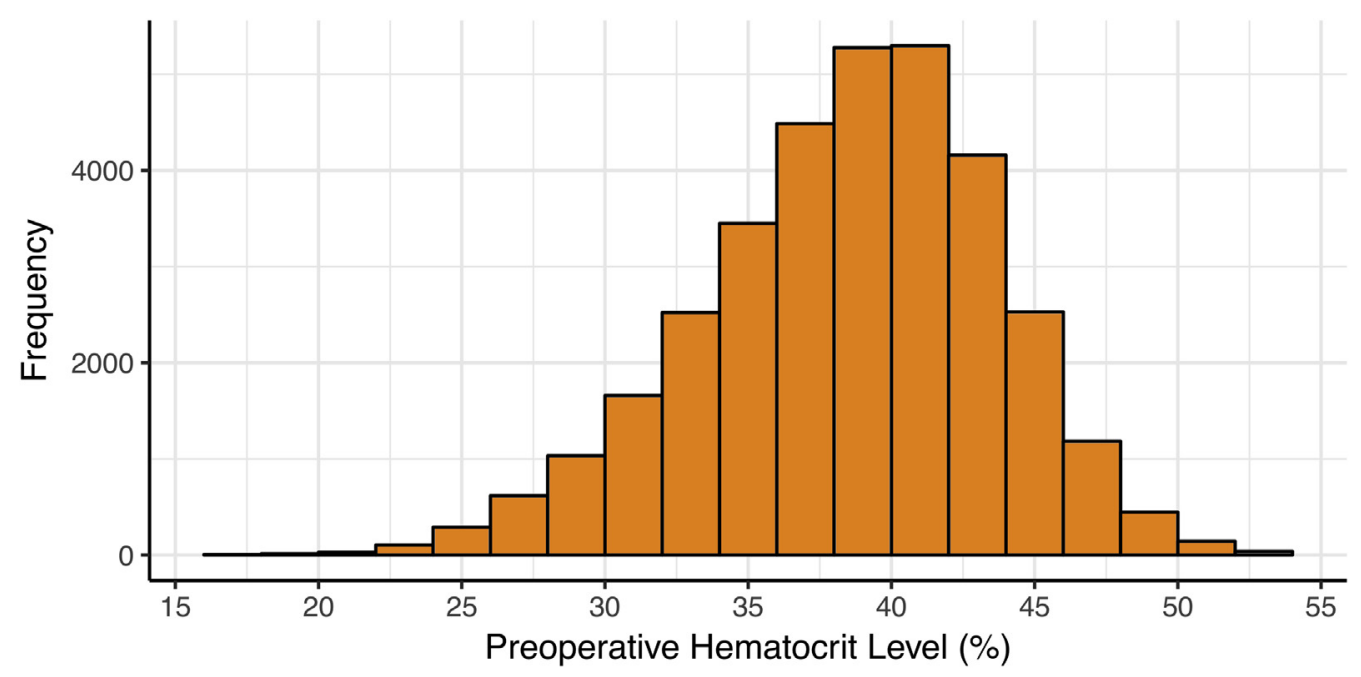

FIGURE 1. Histogram displaying the distribution of preoperative hematocrit levels.

\section{Adjusted Relationships Between Preoperative Hematocrit Level Versus PRBC Transfusion and Mortality and Morbidity}

The relative strengths of association between riskadjusted outcomes and the effect of preoperative Hct level versus PRBC transfusion are displayed in Table 3 with the respective adjusted ORs, $P$ values, and AUC values estimated from each regression model for the outcomes of operative mortality, postoperative renal failure, and postoperative stroke. Complete covariate information is available for each model in Tables E2-E4. A strong association was observed between preoperative Hct and the likelihood of PRBC transfusion (OR, 0.82; 95\% CI, 0.82-0.83; $P<.001)$. After risk adjustment using the STS predicted risk of mortality, PRBC transfusion, but not Hct, demonstrated stronger associations with postoperative mortality (OR, 4.3; $P<.0001)$, renal failure (OR, 6.3;

TABLE 2. Unadjusted incidence of postoperative events and complications following primary, isolated CABG operations $(\mathrm{n}=\mathbf{3 3}, \mathbf{4 1 1})$

\begin{tabular}{lc}
\hline \multicolumn{1}{c}{ Outcome } & Value \\
\hline Any PRBC transfusion, n (\%) & $10,747(31.4)$ \\
Transfused PRBC, units, median (IQR) & $2(1-4)$ \\
\hline Atrial fibrillation, n (\%) & $6821(20.4)$ \\
\hline Stroke, n (\%) & $431(1.3)$ \\
\hline Cardiac arrest, n (\%) & $461(1.4)$ \\
\hline Pneumonia, n (\%) & $707(2.1)$ \\
\hline Prolonged mechanical ventilation, n (\%) & $2887(8.7)$ \\
Renal failure, n (\%) & $923(2.8)$ \\
\hline Hemodialysis, n (\%) & $461(1.4)$ \\
\hline Operative mortality, n (\%) & $667(2.0)$ \\
\hline$P R B C$, Packed red blood cells; IQR, interquartile range.
\end{tabular}

$P R B C$, Packed red blood cells; $I Q R$, interquartile range.
$P<.0001)$, and stroke (OR, 2.4; $P<.0001)$. Although less strongly associated than PRBC transfusion, a 1-point increase in preoperative Hct was associated with a significantly decreased probability of mortality (OR, 0.97; $P=.00011)$ and renal failure (OR, 0.94; $P<2 \mathrm{e}-16)$. The PRBC models performed significantly better than the Hct models for mortality (AUC, 0.82693 vs 0.78886 ; $P<.0001$ ), renal failure (AUC, 0.86063 vs 0.82067 ; $P<.0001)$, and stroke (0.72062 vs $0.69487 ; P=.0013)$.

The adjusted associations between preoperative Hct and the probability of mortality, postoperative PRBC transfusion, and postoperative renal failure are shown in Figure 2. Most importantly, these functions demonstrated that in an otherwise average patient preoperative anemia compared with an Hct level of $40 \%$ was associated with an almost 4- fold increase in the probability of PRBC transfusion, a 3-fold increase in renal failure, and a nearly doubled risk of mortality (Table 4).

\section{DISCUSSION}

The present study reports on risk-adjusted relationships between postoperative mortality and morbidity as a function of preoperative Hct versus PRBC transfusion to better determine which factor confers a greater risk to patients undergoing $\mathrm{CABG}$ surgery. In this multi-institution analysis of more than 33,000 patient records, primary isolated CABG surgeries were evaluated to avoid the potential confounding effects on blood product requirements common during reoperations and combined procedures. As a result, the primary results demonstrate that although preoperative Hct and, more importantly, preoperative anemia are both associated with an increase in risk-adjusted mortality and morbidity, the effect of PRBC transfusion on patient outcomes is more profound. These results address an illdefined issue within cardiac surgical critical care to identify 
TABLE 3. Risk-adjusted impact of preoperative Het and PRBC transfusion on postoperative mortality, renal failure, and stroke

\begin{tabular}{|c|c|c|c|c|c|c|}
\hline \multirow[b]{2}{*}{ Outcome } & \multicolumn{3}{|c|}{ Preoperative Hct model } & \multicolumn{3}{|c|}{ PRBC transfusion model } \\
\hline & $\overline{\text { aOR }(95 \% \mathrm{CI})}$ & $P$ value & $\overline{\text { AUC }}$ & $\overline{\text { aOR }(95 \% \text { CI })}$ & $P$ value & $\overline{\text { AUC }}$ \\
\hline Mortality & $0.97(0.96-0.99)$ & .0001 & 0.789 & $4.25(3.47-5.19)$ & $<.0001$ & 0.827 \\
\hline Renal failure & $0.94(0.93-0.96)$ & $<.0001$ & 0.821 & $6.29(5.24-7.56)$ & $<.0001$ & 0.861 \\
\hline Stroke & $1.02(1.00-1.04)$ & .062 & 0.695 & $2.35(1.90-2.92)$ & $<.0001$ & 0.721 \\
\hline
\end{tabular}

Models adjusted for confounding influence of other covariates: Society of Thoracic Surgeons predicted risk indices (mortality, renal failure, and stroke), operative year, and hospital. Hct, Hematocrit; PRBC, packed red blood cells; $a O R$, adjusted odds ratio; $C I$, confidence interval; $A U C$, area under the curve.

which factor is the greater culprit for worse outcomes following cardiac surgery.

The risk-adjusted impact of preoperative Hct on mortality and morbidity in the present analysis is consistent with previous reports in patients undergoing cardiac surgery. Several studies have demonstrated a significant correlation between either preoperative or intraoperative anemia and adverse cardiac surgical outcomes. ${ }^{17-20}$ van Straten and colleagues ${ }^{20}$ identified preoperative anemia as a significant risk factor for early and late mortality in a heterogeneous population of 10,025 cardiac surgery recipients. Similarly, in an analysis of 3500 patients, Karkouti and colleagues ${ }^{18}$ demonstrated a 2-fold increase in the risk-adjusted odds of composite mortality, stroke, and renal injury in patients with preoperative anemia. An international analysis of more than 5000 patients corroborated these findings in a multi-institution (70 centers) cohort of patients. ${ }^{19}$ In addition, the strong correlation between preoperative Hct level and the likelihood of postoperative PRBC transfusion in the present study is consistent with the primary results of former analyses. ${ }^{17}$ The results of the present study extend those of former reports, and also address several limitations of previous analyses, including the risk-adjusted hierarchical modeling of preoperative Hct as a continuous function to better understand the relationship between declining Hct level and perioperative mortality and morbidity. These results also provide an analysis of primary, isolated CABG operations alone to avoid the inherent confounding that is often difficult to adjust for in heterogeneous patient populations. Although the impact of intraoperative anemia was not specifically examined in this analysis, previous large cohort studies have demonstrated that nadir Hct levels during cardiopulmonary bypass significantly impact postoperative mortality. ${ }^{21-23}$

The main results of this study demonstrate that PRBC transfusion has a greater effect than preoperative Hct on the likelihood of postoperative mortality, stroke, and renal failure after adjustment for the confounding influence of baseline patient risk profile, differences at the hospital level, and year of operation. These conclusions are based on the significantly higher strength of association (as determined by $P$ values and model AUC) estimated for the effect of PRBC transfusion (compared with preoperative Hct) with each outcome. Although several previous analyses have demonstrated the adverse impact of either anemia or blood transfusions alone on mortality and morbidity, ${ }^{5,8,24-26}$ our study design is unique in that it more directly addresses the question of which factor (anemia vs transfusion) contributes more to poor patient outcomes. This methodology and results are important, demonstrating that although anemia and PRBC transfusion are often clinically related events, the estimated negative impact of PRBC transfusion is greater, and efforts to avoid transfusion when clinically feasible should be considered.

The present results have significant clinical implications related to the perioperative management of patients undergoing surgical myocardial revascularization. A fundamental limitation of any analysis of blood product utilization after cardiac surgery is the criticism that the number of blood product transfusions likely represents a surrogate for sicker patient populations compared with patients not requiring blood products. This factor has been addressed in many former risk-adjusted and propensity score cohort matched analyses. ${ }^{5,8,24-26}$ While a legitimate concern, results of these analyses, as well as the present, have consistently identified transfusion as an independent risk factor for mortality. As a result, our demonstration of a highly significant and strong association between preoperative Hct and the likelihood of PRBC transfusion further supports the critical role of proper preoperative planning and correction of preoperative anemia when possible to avoid the untoward effects of PRBC transfusion following cardiac surgery. Thus, these results further corroborate blood conservation efforts and guidelines advanced by the STS and Society of Cardiovascular Anesthesiologists, including (1) efforts designed to increase preoperative blood volume (eg, erythropoietin, autologous preoperative blood donation), (2) intraoperative blood conservation and cell-saving devices, (3) interventions to avoid operative stress, (4) implementation of institution-specific transfusion algorithms, (5) use of multimodal blood conservation techniques, and (6) use of miniaturized cardiopulmonary bypass circuits and modified ultrafiltration to maximize intraoperative and postoperative Hct levels. ${ }^{27,28}$ In addition, the results of this study further highlight the importance of focusing on blood conservation efforts, given that previous reports have demonstrated the significantly increased economic burden of blood product transfusion on healthcare costs after cardiac surgery. ${ }^{8,25}$ 


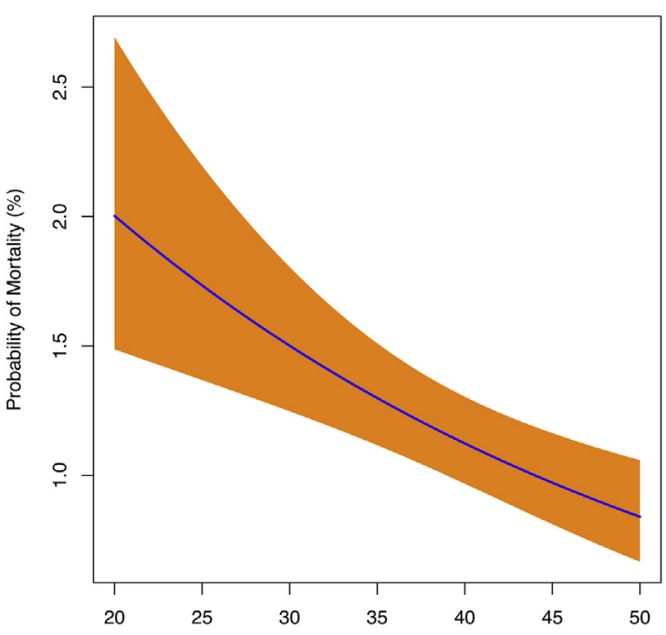

A

Preoperative Hematocrit
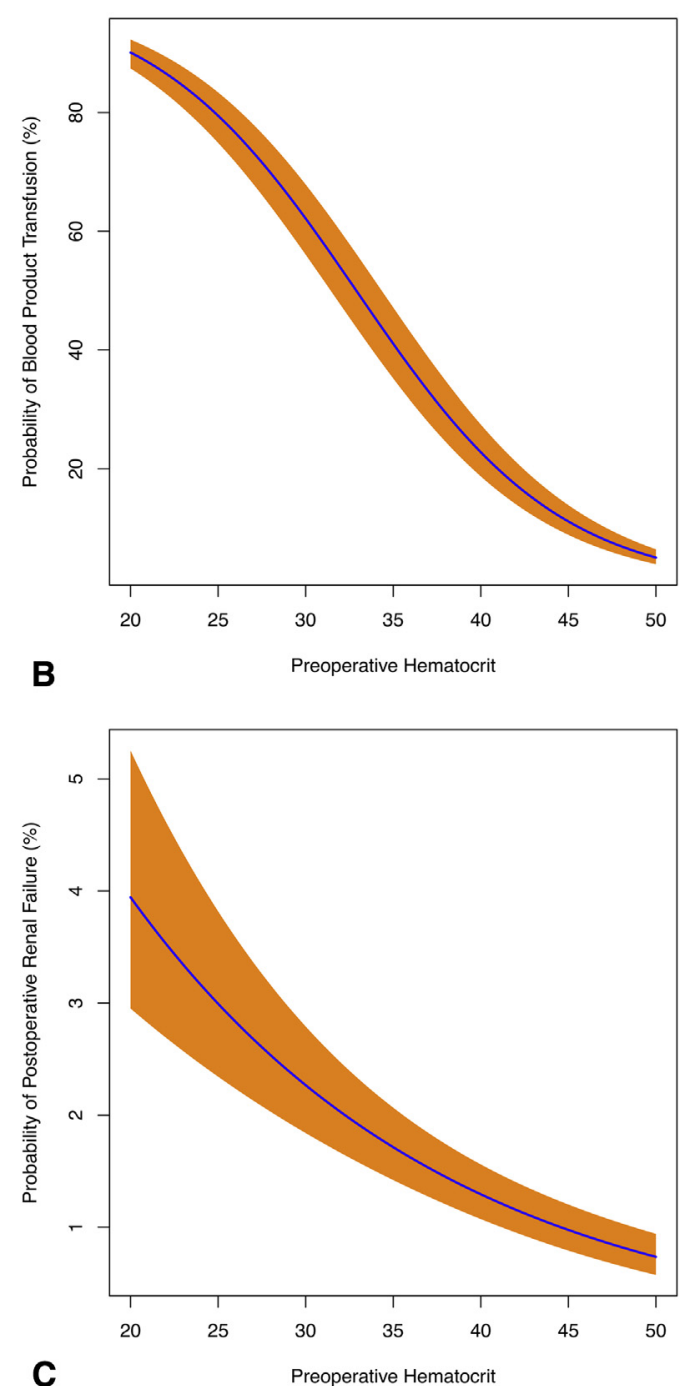

FIGURE 2. A, Risk-adjusted model of the impact of preoperative hematocrit (Hct) versus the probability of mortality following primary, isolated coronary artery bypass grafting (CABG) surgery. The $95 \%$ confidence in-
TABLE 4. Impact of preoperative anemia (compared with preoperative Hct of $40 \%$ ) on predicted probabilities of postoperative PRBC transfusion, renal failure, and mortality

\begin{tabular}{lccc}
\hline & \multicolumn{3}{c}{ Predicted probability, \% } \\
\cline { 2 - 4 } Postoperative outcome & Heoperative & Preoperative & Preoperative \\
Hct 30\% & Hct 40\% \\
\hline PRBC transfusion & 90.1 & 62.1 & 22.8 \\
Renal failure & 3.9 & 2.3 & 1.3 \\
Mortality & 2.0 & 1.5 & 1.1 \\
\hline
\end{tabular}

Hct, Hematocrit; $P R B C$, packed red blood cells.

This study has some noteworthy limitations. The retrospective study design introduces inherent selection bias. The results reported here reflect observed associations between modeled factors and outcomes, but do not demonstrate direct cause-and-effect relationships. An additional limitation concerns the methods used to measure and report preoperative Hct. Measurements of a single, preoperative blood Hct level as opposed to alternative measurements (eg, average Hct) may overestimate or underestimate the relationships between preoperative Hct or degree of anemia and measured outcomes. Furthermore, the impact of transfusions performed in the preoperative setting in an effort to correct anemia and optimize preoperative status could not be determined or analyzed. The deidentified nature of a large data registry is inherently limited to the analysis of predefined variables, variable definitions, and variable granularity. As a result, it was not possible to directly analyze the impact of anemia or transfusion on the likelihood of transfusion-related acute lung injury, infectious complications, or transfusion reactions. Timing of blood transfusion was not captured in the VCSQI data registry, a limitation of currently captured data in the STS national database as well. Although outside the scope of this analysis, additional investigation of the impact of other blood products on outcomes would be beneficial. The study is constrained by a lack of long-term reports of outcomes. Unrecognized miscoding of data must also be considered in any secondary analysis of a data registry. Finally, risk adjustment using the STS predicted risk of mortality might not completely account for association of postoperative complications and transfusion requirements. Despite these limitations, this analysis provides a robust analysis of the largest multiinstitution cohort of CABG recipients reported to date with the specific aim of determining the relative clinical impact of preoperative Hct level versus PRBC transfusion.

terval is represented in orange. B, Risk-adjusted model of the impact of preoperative Hct versus the probability of packed red blood cell (PRBC) transfusion following primary, isolated CABG. C, Risk-adjusted model of the impact of preoperative Hct versus the probability of postoperative renal failure following primary, isolated $\mathrm{CABG}$. 


\section{CONCLUSIONS}

The primary results of this multi-institution analysis of CABG outcomes demonstrate that PRBC transfusion is more strongly associated with risk-adjusted morbidity and mortality compared with preoperative Hct level alone. Preoperative anemia independently increases the risk of postoperative morbidity and mortality, but more strongly increases the likelihood of postoperative PRBC transfusion. Therefore, our data support efforts to reduce unnecessary PRBC transfusions. Our results suggest that preoperative Hct levels should be considered for inclusion in the STS risk calculators. Finally, efforts to optimize preoperative Hct to avoid anemia should be investigated as a potentially modifiable risk factor for morbidity and mortality.

\section{Webcast}

You can watch a Webcast of this AATS meeting presentation by going to: http://webcast.aats.org/2015/Video/ Monday/04-27-15_608_1415_LaPar.mp4.

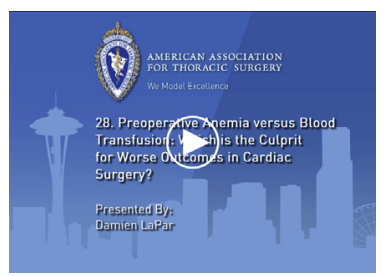

\section{Conflict of Interest Statement}

Authors have nothing to disclose with regard to commercial support.

\section{References}

1. Speiss BD. Transfusion and outcome in heart surgery. Ann Thorac Surg. 2002;74: 986-7.

2. Rogers MA, Blumberg N, Saint S, Langa KM, Nallamothu BK. Hospital variation in transfusion and infection after cardiac surgery: a cohort study. BMC Med. 2009; 7:37.

3. Stover EP, Siegel LC, Parks R, Levin J, Body SC, Maddi R, et al. Variability in transfusion practice for coronary artery bypass surgery persists despite national consensus guidelines: a 24-institution study. Institutions of the multicenter study of perioperative ischemia research group. Anesthesiology. 1998;88:327-33.

4. Banbury MK, Brizzio ME, Rajeswaran J, Lytle BW, Blackstone EH. Transfusion increases the risk of postoperative infection after cardiovascular surgery. J Am Coll Surg. 2006;202:131-8.

5. Engoren MC, Habib RH, Zacharias A, Schwann TA, Riordan CJ, Durham SJ. Effect of blood transfusion on long-term survival after cardiac operation. Ann Thorac Surg. 2002; 74:1180-6.

6. Koch CG, Li L, Duncan AI, Mihaljevic T, Cosgrove DM, Loop FD, et al. Morbidity and mortality risk associated with red blood cell and bloodcomponent transfusion in isolated coronary artery bypass grafting. Crit Care Med. 2006;34:1608-16.

7. Koch CG, Li L, Duncan AI, Mihaljevic T, Loop FD, Starr NJ, et al. Transfusion in coronary artery bypass grafting is associated with reduced longterm survival. Ann Thorac Surg. 2006;81:1650-7.

8. Murphy GJ, Reeves BC, Rogers CA, Rizvi SI, Culliford L, Angelini GD. Increased mortality, postoperative morbidity, and cost after red blood cell transfusion in patients having cardiac surgery. Circulation. 2007;116:2544-52.

9. Scott BH, Seifert FC, Grimson R. Blood transfusion is associated with increased resource utilisation, morbidity and mortality in cardiac surgery. Ann Card Anaesth. 2008;11:15-9.
10. Surgenor SD, DeFoe GR, Fillinger MP, Likosky DS, Groom RC, Clark C, et al. Intraoperative red blood cell transfusion during coronary artery bypass graft surgery increases the risk of postoperative low-output heart failure. Circulation. 2006;114(1 Suppl):I43-8.

11. Surgenor SD, Kramer RS, Olmstead EM, Ross CS, Sellke FW, Likosky DS, et al. The association of perioperative red blood cell transfusions and decreased long-term survival after cardiac surgery. Anesth Analg. 2009; 108:1741-6.

12. Spiess BD. Blood transfusion: the silent epidemic. Ann Thorac Surg. 2001;72: S1832-7.

13. Taylor RW, O'Brien J, Trottier SJ, Manganaro L, Cytron M, Lesko MF, et al. Red blood cell transfusions and nosocomial infections in critically ill patients. Crit Care Med. 2006;34:2302-8. quiz 2309.

14. Toy P, Lowell C. TRALI: definition, mechanisms, incidence and clinical relevance. Best Pract Res Clin Anaesthesiol. 2007;21:183-93.

15. Koch CG, Khandwala F, Li L, Estafanous FG, Loop FD, Blackstone EH. Persistent effect of red cell transfusion on health-related quality of life after cardiac surgery. Ann Thorac Surg. 2006;82:13-20.

16. Society of Thoracic Surgeons. Executive summary 2012. Available at: http:// www.sts.org/sts-national-database/database-managers/executive-summaries. Accessed: May 5, 2014.

17. Hung M, Besser M, Sharples LD, Nair SK, Klein AA. The prevalence and association with transfusion, intensive care unit stay and mortality of preoperative anaemia in a cohort of cardiac surgery patients. Anaesthesia. 2011;66:812-8.

18. Karkouti K, Wijeysundera DN, Beattie WS, Reducing Bleeding in Cardiac Surgery I. Risk associated with preoperative anemia in cardiac surgery: a multicenter cohort study. Circulation. 2008;117:478-84.

19. Kulier A, Levin J, Moser R, Rumpold-Seitlinger G, Tudor IC, Snyder-Ramos SA, et al. Impact of preoperative anemia on outcome in patients undergoing coronary artery bypass graft surgery. Circulation. 2007;116:471-9.

20. van Straten AH, Hamad MA, van Zundert AJ, Martens EJ, Schonberger JP, de Wolf AM. Preoperative hemoglobin level as a predictor of survival after coronary artery bypass grafting: a comparison with the matched general population. Circulation. 2009; 120:118-25.

21. DeFoe GR, Ross CS, Olmstead EM, Surgenor SD, Fillinger MP, Groom RC, et al. Lowest hematocrit on bypass and adverse outcomes associated with coronary artery bypass grafting. Northern New England cardiovascular disease study group. Ann Thorac Surg. 2001;71:769-76.

22. Karkouti K, Djaiani G, Borger MA, Beattie WS, Fedorko L, Wijeysundera D, et al. Low hematocrit during cardiopulmonary bypass is associated with increased risk of perioperative stroke in cardiac surgery. Ann Thorac Surg. 2005;80:1381-7.

23. Loor G, Li L, Sabik JF III, Rajeswaran J, Blackstone EH, Koch CG. Nadir hematocrit during cardiopulmonary bypass: end-organ dysfunction and mortality. J Thorac Cardiovasc Surg. 2012;144:654-62.

24. Kuduvalli M, Oo AY, Newall N, Grayson AD, Jackson M, Desmond MJ, et al Effect of peri-operative red blood cell transfusion on 30-day and 1-year mortality following coronary artery bypass surgery. Eur J Cardiothorac Surg. 2005;27: 592-8.

25. LaPar DJ, Crosby IK, Ailawadi G, Ad N, Choi E, Spiess BD, et al. Blood product conservation is associated with improved outcomes and reduced costs after cardiac surgery. J Thorac Cardiovasc Surg. 2013;145:796-803; discussion 803-4.

26. van Straten AH, Bekker MW, Soliman Hamad MA, van Zundert AA, Martens EJ, Schonberger JP, et al. Transfusion of red blood cells: the impact on short-term and long-term survival after coronary artery bypass grafting, a ten-year follow-up. Interact Cardiovasc Thorac Surg. 2010;10:37-42.

27. Society of Thoracic Surgeons Blood Conservation Guideline Task Force, Ferraris VA, Ferraris SP, Saha SP, Hessel EA II, Haan CK, et al. 2011 update to the Society of Thoracic Surgeons and the Society of Cardiovascular Anesthesiologists blood conservation clinical practice guidelines. Ann Thorac Surg. 2011;91:944-82.

28. Society of Thoracic Surgeons Blood Conservation Guideline Task Force, Ferraris VA, Ferraris SP, Saha SP, Hessel EA II, Haan CK, et al. Perioperative blood transfusion and blood conservation in cardiac surgery: the Society of Thoracic Surgeons and the Society of Cardiovascular Anesthesiologists clinical practice guideline. Ann Thorac Surg. 2007;83(5 Suppl):S27-86.

Key Words: anemia, cardiac, CABG, hematocrit, transfusion 
Discussion

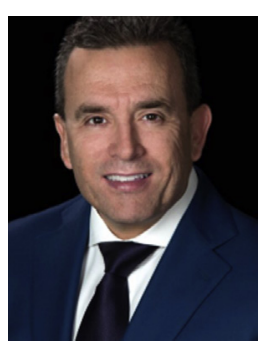

Dr Juan B. Grau (Ridgewood, NJ). I want to thank the Association for the opportunity to discuss this abstract and the authors for sending me the manuscript prior to the meeting. This is an important work which seeks to investigate the relative importance of preoperative anemia and transfusion, both negative preoperative predictive factors on morbidity and mortality after CABG.

In summary, this is a multicenter evaluation of the impact of preoperative hematocrit and postoperative red blood cell transfusion in 21,641 patients after CABG, and what the authors' goal was, was to determine which of these factors is more highly associated with mortality and morbidity after CABG. The authors use statistical techniques to control for patient factors, surgeon, institution, and the year of surgery in evaluating the effects of preoperative hematocrit and red blood cell transfusion.

They found that lower preoperative hematocrit level was related to the likelihood of red blood cell transfusion. In risk-adjusted analyses, they showed that red blood cell transfusion was highly associated with an increase in mortality, postoperative renal failure, and stroke.

Decreasing preoperative hematocrit was associated with increased mortality and renal failure, but the strength of this association was less than that found for red blood cell transfusion. In addition, the authors noted that preoperative anemia was associated with increased probability of transfusion, renal failure, and mortality, which is not surprising.

They conclude that red blood cell transfusion is highly related to poor outcomes and that transfusions should be limited, and efforts should be made to treat preoperative anemia. They also suggest that preoperative hematocrit levels should be considered for inclusion in the STS risk calculators.

The authors' work relies heavily on statistical control to support the final conclusions. Given this, it would have been helpful to see the full models that were used for this study, including the likelihood ratios for the patient risk, surgeon, institution and year of surgery. Also, the authors are using the likelihood ratio to compare across these models. It would have been worthwhile to see both factors, hematocrit and blood transfusion in the same model and to compare the patients who were transfused to those who were not transfused to better understand how this work compares to others that have been reported in the literature.

And I have four questions for the presenter. Number one, anemia is an important concept, but it is not clear how it was defined in your study or how standardly it was assessed across multiple sites. Can you comment?
Number two- -should I ask one and then answer or whatever you prefer?

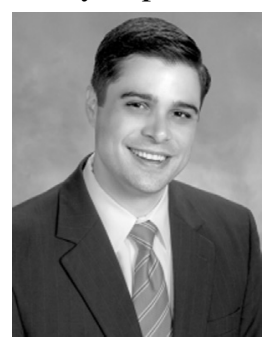

Dr Damien J. LaPar (Charlottesville, Va). I'll go ahead and take the first one. Thank you very much for your commentary, for your time, and for your kind comments related to our work.

In our study, we didn't arbitrarily define a threshold for anemia in the study. Rather, we evaluated the continuous, nonlinear relationship between preoperative hematocrit and outcomes. As demonstrated in the figures I presented, low hematocrit levels meeting traditional standards for anemia had higher associations with morbidity and mortality.

Dr Grau. So there's not a single number?

Dr LaPar. No, sir.

Dr Grau. Number two, the statistical approach used involved developing separate models for the effect of hematocrit and red blood cell transfusion, using the likelihood ratio to compare. Did you do any analysis including both factors in the same model?

Dr LaPar. No we didn't do that. Our choice to analyze each factor separately was predicated upon the desire to eliminate any collinearity in our models between these two factors.

Dr Grau. I didn't see discussion of an "interaction," which is a formal statistical term in the multivariate regression analysis, which is very different from a "correlation" between anemia and transfusion with respect to the outcome variables, mortality and morbidity. In other words, did the significance of either variable vary as a function of the value of the other variable, number one? And number two, was a formal test done for a significant interaction performed, and if so, what was the result?

Dr LaPar. We did not include interaction terms between the 2 factors in our model. Certainly, that is a valid statistical method to account for any correlation between the 2 effects. My suspicion would be that inclusion of an interaction term in our model would result a highly significant relationship with packed red blood cell transfusion, but it would have probably diluted the effect alone of the level of preoperative hematocrit. I'm sure that the interaction term between the 2 factors probably would have been highly significant as well.

Dr Grau. And a final question, do you analyze the impact of comprehensive multimodality blood conservation programs to decrease the incidence of transfusion in the centers that had such programs in place in your study?

Dr LaPar. I'm sorry, I missed the beginning of your question.

Dr Grau. Did you analyze the impact of a comprehensive multimodality blood conservation program in the centers that-I'm sure all the 19 or 18 centers that you had, 
some of them had and some of them didn't. The ones that had them, did you analyze them independently?

Dr LaPar. We did not do any analyses of individual hospitals. As you mentioned, there are hospitals within our organization that have various protocols. As an initiative overall, we've looked at blood product utilization in the past, and we've implemented comprehensive protocols for blood product conservation in some of our institutions.

Dr Grau. Excellent presentation and very good answers. Thank you. 
TABLE E1. Number and percentage of total for missing baseline data

\begin{tabular}{lc}
\hline \multicolumn{1}{c}{ Characteristics } & Missing, $\mathbf{n}(\%)$ \\
\hline Patient characteristics & \\
Age & $0(0)$ \\
Female sex & $0(0)$ \\
Body mass index & $9(0.03)$ \\
Cerebrovascular disease & $82(0.2)$ \\
Stroke & $1089(3.3)$ \\
Chronic lung disease & $688(2.1)$ \\
Hypertension & $10(0.03)$ \\
Diabetes & $11(0.03)$ \\
Peripheral arterial disease & $46(0.1)$ \\
Renal failure (hemodialysis) & $21(0.06)$ \\
NYHA class & $507(1.5)$ \\
Ejection fraction & $711(2.1)$ \\
Left main disease $>50 \%$ & $9711(29.1)$ \\
Number of disease vessels & $115(0.3)$ \\
Last preoperative Hct & $0(0)$ \\
Predicted risk of mortality & $0(0)$ \\
Operative characteristics & \\
Cardiopulmonary bypass support & $1(0.003)$ \\
Operative status & $6(0.02)$ \\
Cardiopulmonary bypass time & $73(0.2)$ \\
Aortic cross-clamp time & $8(0.02)$ \\
Lowest intraoperative Hct & $12,181(36.5)$ \\
Internal mammary artery use & $25(0.07)$ \\
\hline
\end{tabular}

NYHA, New York Heart Association; Hct, hematocrit.
TABLE E3. Intraoperative and postoperative transfusion frequencies

\begin{tabular}{lccc}
\hline $\begin{array}{c}\text { PRBC units } \\
\text { transfused }\end{array}$ & $\begin{array}{c}\text { Intraoperative, } \\
\mathbf{n}(\%)\end{array}$ & $\begin{array}{c}\text { Postoperative, } \\
\mathbf{n}(\%)\end{array}$ & $\begin{array}{c}\text { Total, } \\
\mathbf{n}(\%)\end{array}$ \\
\hline 0 & $29,090(87.1)$ & $24,729(74.0)$ & $22,912(68.6)$ \\
1 & $1655(5.0)$ & $3106(9.3)$ & $2950(8.8)$ \\
\hline 2 & $1759(5.3)$ & $3004(9.3)$ & $3457(10.4)$ \\
3 & $437(1.3)$ & $1013(3.0)$ & $1442(4.3)$ \\
$4+$ & $452(1.4)$ & $1552(4.7)$ & $2625(7.9)$ \\
\hline
\end{tabular}

PRBC, Packed red blood cells.
TABLE E2. Number and percentage of total for missing outcomes data

\begin{tabular}{lc}
\hline \multicolumn{1}{c}{ Outcome } & Missing, $\mathbf{n}(\%)$ \\
\hline Intraoperative PRBC transfusion & $18(0.05)$ \\
\hline Postoperative PRBC transfusion & $7(0.02)$ \\
\hline Atrial fibrillation & $13(0.04)$ \\
Stroke & $22(0.07)$ \\
Cardiac arrest & $15(0.04)$ \\
Pneumonia & $42(0.1)$ \\
\hline Prolonged mechanical ventilation & $16(0.05)$ \\
Renal failure & $16(0.05)$ \\
\hline Hemodialysis & $20(0.06)$ \\
Operative mortality & $34(0.1)$ \\
\hline In-hospital mortality & $0(0)$ \\
\hline$P R B C$, Packed red blood cells. &
\end{tabular}

TABLE E4. Risk-adjusted impact of preoperative Het and PRBC transfusion on postoperative mortality

\begin{tabular}{lccc}
\hline \multicolumn{1}{c}{ Model } & aOR & $\mathbf{9 5} \%$ CI & $\boldsymbol{P}$ value \\
\hline Hematocrit model & & & \\
Centered Hct & 0.97 & $0.96-0.99$ & .0001 \\
Logit(PROM) & 2.64 & $2.46-2.83$ & $<.0001$ \\
Year & 0.95 & $0.92-0.97$ & .0001 \\
Intercept & 0.93 & $0.70-1.24$ & .637 \\
PRBC model & & & \\
PRBC transfusion & 4.25 & $3.47-5.19$ & $<.0001$ \\
Logit(PROM) & 2.22 & $2.07-2.39$ & $<.0001$ \\
Year & 0.98 & $0.95-1.01$ & .179 \\
Intercept & 0.22 & $0.15-0.31$ & $<.0001$ \\
\hline
\end{tabular}

Each model additionally accounts for hospital as a random effect. $a O R$, Adjusted odd ratio; $C I$, confidence interval; Hct, hematocrit; PROM, predicted risk of mortality; $P R B C$, packed red blood cells. 
TABLE E5. Risk-adjusted impact of preoperative Hct and PRBC transfusion on renal failure

\begin{tabular}{lll}
\hline \multicolumn{1}{c}{ Model } & aOR $(\mathbf{9 5} \% \mathbf{C I})$ & $\boldsymbol{P}$ value \\
\hline Hematocrit model & & \\
Centered Hct & $0.94(0.93-0.96)$ & $<.0001$ \\
Logit(PRORF) & $2.62(2.45-2.80)$ & $<.0001$ \\
Year & $0.89(0.87-0.92)$ & $<.0001$ \\
$\quad$ Intercept & $0.53(0.41-0.69)$ & $<.0001$ \\
Transfusion model & & \\
PRBC transfusion & $6.29(5.24-7.56)$ & $<.0001$ \\
Logit(PRORF) & $2.30(2.16-2.46)$ & $<.0001$ \\
Year & $0.93(0.90-0.95)$ & $<.0001$ \\
Intercept & $0.13(0.10-0.18)$ & $<.0001$ \\
\hline
\end{tabular}

Each model additionally accounts for hospital as a random effect. $a O R$, Adjusted odds ratio; $C I$, confidence interval; $H c t$, hematocrit; $P R O R F$, predicted risk of renal failure; $P R B C$, packed red blood cells.

TABLE E6. Risk-adjusted impact of preoperative Het and PRBC transfusion on stroke

\begin{tabular}{lcc}
\hline \multicolumn{1}{c}{ Model } & aOR $(\mathbf{9 5} \% \mathbf{C I})$ & $\boldsymbol{P}$ value \\
\hline Hematocrit model & & \\
Centered Hct & $1.02(1.00-1.04)$ & .062 \\
Logit(PROS) & $2.60(2.26-2.98)$ & $<.0001$ \\
Year & $0.94(0.90-0.97)$ & .0002 \\
Intercept & $0.89(0.49-1.62)$ & .695 \\
Transfusion model & & \\
PRBC transfusion & $2.35(1.90-2.92)$ & $<.0001$ \\
Logit(PROS) & $1.97(1.72-2.27)$ & $<.0001$ \\
Year & $0.96(0.93-1.00)$ & .034 \\
Intercept & $0.18(0.09-0.34)$ & $<.001$ \\
\hline
\end{tabular}

Each model additionally accounts for hospital as a random effect. $a O R$, Adjusted odds ratio; $C I$, confidence interval; $H c t$, hematocrit; $P R O S$, predicted risk of stroke; $P R B C$, packed red blood cells. 